\title{
Síntesis de nanopartículas de plata reducidas con desecho producido por el insecto Ulomoides dermestoides
}

\section{Synthesis of silver nanoparticles reduced by the waste produced from Ulomoides dermestoides}

RAMOS-VILLA, Isabel $\uparrow$, LOMELÍ-ROSALES, Diego Alberto, VELASCO-RAMÍREZ, Sandra Fabiola y VELAZQUEZ-JUAREZ, Gilberto*

Universidad de Guadalajara. Centro Universitario de Ciencias Exactas e Ingenierías. Departamento de Química. Guadalajara Jalisco, México

ID $1^{\text {er }}$ Autor: Isabel, Ramos-Villa / ORC ID: 0000-0001-9229-0938, CVU CONACYT ID: 1000225

ID $1^{\text {er }}$ Coautor: Diego Alberto, Lomelí-Rosales / ORC ID: 0000-0002-9949-5829, CVU CONACYT ID: 552256

ID $2^{\text {do }}$ Coautor: Sandra Fabiola, Velasco-Ramírez / ORC ID: 0000-0002-7054-1465, CVU CONACYT ID: 167305

ID $3^{\text {er }}$ Coautor: Gilberto, Velazquez-Juarez / ORC ID: 0000-0002-1130-4021, CVU CONACYT ID: 228315

DOI: 10.35429/JCPE.2019.18.6.19.36

Recibido 09 Febrero, 2019; Aceptado 28 Marzo, 2019

\begin{abstract}
Resumen
La escala de la Nanotecnología es de alrededor de $0,2 \mathrm{~nm}$ hasta aproximadamente $100 \mathrm{~nm}$ y son utilizadas en muy diversas disciplinas. El $U$. dermestoides es un coleóptero que pertenece a la familia Tenebrionidae, comúnmente reconocidos como escarabajos oscuros, de hábitos fitófagos. En el desecho se han identificado en mayor cantidad los siguientes compuestos orgánicos: saponinas, cumarinas, esteroides, fenoles, alcaloides, proteínas y aminoácidos. Se realizó la síntesis de nanopartículas de plata mediante solución coloidal a partir de la reducción de nitrato de plata, a diferentes concentraciones, utilizando el desecho del insecto $U$. dermestoides con tres diferentes dietas: centeno y manzana; avena, pan y manzana y por último pan y manzana. Se realizaron una serie de pruebas cualitativas, determinándose la presencia de fenoles, alcaloides, carbohidratos, proteínas y aminoácidos. Se utilizó espectrofotometría UV-vis en el rango de 200-800 $\mathrm{nm}$. Los resultados muestran que entre $400-450 \mathrm{~nm}$ se forma un pico de la resonancia de plasmón superficial, el cual indica la formación de las nanopartículas de plata. Mediante la microscopia electrónica de barrido (SEM) se observó la presencia de nanopartículas de plata de forma esférica y con la microscopia electrónica por transmisión (TEM) se confirmó la presencia y la forma de las nanopartículas.
\end{abstract}

Nanoparticulas, Ulomoides, Síntesis verde

\begin{abstract}
The scale of nanotechnology goes from $0.2 \mathrm{~nm}$ to approximately $100 \mathrm{~nm}$ and is used in many different disciplines. U.dermestoides is a beetle belonging to the family Tenebrionidae,commonly known as darkling beetles, it has phytophagous habits. In its waste have been identified the following organic compounds: Saponins, coumarins, steroids, phenols, alkaloids, proteins and amino acids. The synthesis of silver nanoparticles was done using colloidal solution from the reduction of silver nitrate at different concentrations, using U. dermestoides waste from three different diets: Rye and Apple; oats, bread and Apple and finally bread and Apple. Series of qualitative tests were done to determinate the presence of phenols, alkaloids carbohydrates, proteins and amino acids. UV-vis spectrophotometry was used in a range from 200 to $800 \mathrm{~nm}$. The results show that between $400-450 \mathrm{~nm}$ there is a surface plasmon resonance peak, indicating the formation of silver nanoparticles. By scanning electron microscopy (SEM) the presence of spherical silver nanoparticles was observed and by transmission electron microscopy (TEM) was confirmed the presence and shape of nanoparticles.
\end{abstract}

Nanoparticles, Ulomoides, Green synthesis

Citación: RAMOS-VILLA, Isabel, LOMELÍ-ROSALES, Diego Alberto, VELASCO-RAMÍREZ, Sandra Fabiola y VELAZQUEZ-JUAREZ, Gilberto. Síntesis de nanopartículas de plata reducidas con desecho producido por el insecto Ulomoides dermestoides. Revista de Energía Química y Física. 2019. 6-18: 29-36

\footnotetext{
* Correspondencia al Autor (Correo electrónico: gilberto.velazquez@academicos.udg.mx)

$\dagger$ Investigador contribuyendo como primer Autor
} 


\section{Introducción}

La síntesis verde de nanopartículas ha tomado un impulso importante en la última década, debido a las múltiples aplicaciones en diversas áreas de la tecnología desde el área de biosensores (Conde Delgado, 2019; Gómez-Velasco et al., 2019) hasta la inmunoestimulación de productos alimenticios (Tello Olea, 2018). Es por ello que la búsqueda de nuevas estrategias para la reducción de metales que sean sencillas, económicas y amigables con el medio ambiente ha permitido lograr síntesis eficientes en diversos sistemas, incluyendo el uso de bacterias, levaduras, hongos, microalgas, y plantas o bien extractos obtenidos de los mismos en condiciones acuosas o con solventes poco agresivos para el medio ambiente (Gour \& Jain, 2019; Sharma, Kanchi, \& Bisetty, 2015).

Sin embargo, poco ha sido explorado el empleo de otras fuentes de reductores para la producción de nanopartículas metálicas que además de clasificarse dentro de la síntesis verde, también cumplan con el componente del aprovechamiento integral de los residuos para la generación de un valor agregado (Salari, Danafar, Dabaghi, \& Ataei, 2016).

El insecto Ulomoides dermestoides es un coleóptero que pertenece a la familia Tenebrionidae, comúnmente se le denomina como escarabajo oscuro, posee hábitos fitófagos y se encuentra clasificado como un insecto comestible para el ser humano (Morillo-Garcia, Olivero-Verbel, \& Caballero-Gallardo, 2016). Entre las ventajas que ofrece este insecto como fuente de alimentación es la posibilidad de la crianza en espacios cerrados y con ambientes microbiológicamente controlados.

Como cualquier ser vivo, Ulomoides tiene un proceso de digestión del alimento para la producción de un desecho que queda a disposición de las granjas de insectos (Crespo et al., 2011). Estudios preeliminares sobre este desecho han mostrado una diversidad de componentes que lo hacen desde el punto de vista químico interesante por la riqueza de metabolitos, minerales y proteínas presentes en el desecho (Mlcek, Borkovcova, \& Bednarova, 2014).
El objetivo de esta investigación es evaluar la capacidad reductora de los extractos acuosos del desecho del insecto Ulomoides para estandarizar las condiciones óptimas para la producción de nanopartículas de plata (NPsAg) mediante una síntesis libre de solventes orgánicos y en un sistema económicos, práctico y sencillo.

Es por ello, que en este trabajo decidimos explorar el potencial de los extractos acuosos del desecho del insecto Ulomoides, en condiciones contraladas y reproducibles para la generación de NPsAg. Para ello se realizó la evaluación de diversos desechos generados a partir de diferentes dietas del insecto, buscando las condiciones óptimas para la síntesis de la nanopartícula metálica, se monitoreó la producción de la nanopartícula mediante espectrofotometría UV-VIS en el rango de 200$800 \mathrm{~nm}$, para posterior evaluación por SEM y TEM para la confirmación de la morfología y tamaño de las nanopartículas, asimismo, fue evaluada la actividad antibacteriana presentada por las diversas nanopartículas generadas con los distintos desechos.

\section{Metodología}

\section{Materiales utilizados}

Todos los reactivos fueron utilizados sin previa purificación. El nitrato de plata $\left(\mathrm{AgNO}_{3}\right)$ fue obtenido de Sigma-Aldrich ${ }^{\circledR}$. Se utilizó una autoclave electrónica Lorma ${ }^{\circledR}$ modelo AV28L para la esterilización de los desechos y una lámpara UV modelo F6T5BL JAPAN para la síntesis de nanopartículas. La caracterización de las nanopartículas obtenidas mediante UV-Vis se llevó a cabo en un equipo de Thermo Scientific $^{\mathrm{TM}}$ Espectrofotómetro de UV Vis GENESYSTM $10 \mathrm{~S}$.

La morfología y tamaño fueron caracterizadas por TEM, en un equipo Jeol JEM 2100 instrument operado a $90 \mathrm{kV}$. La caracterización por SEM se llevó a cabo en un Microscopio electrónico de barrido de emisión de campo (FE-SEM) Marca Tescan modelo MIRA 3 LMU, de alta resolución. Se utilizó una incubadora Luzeren FCD-3000 serials a $37^{\circ} \mathrm{C}$ y una cámara de flujo laminar marca Luzeren, modelo BBS-V680 para la incubación y manipulación de las bacterias. 


\section{Extracción de los desechos}

Se dividieron tres grupos de $U$. dermestoides, a los cuales se les alimentó con tres dietas diferentes: a) centeno y manzana «DV1», b) avena, pan y manzana «DV2», Pan y manzana «DN». Para cada grupo, una vez obtenida una cantidad considerable de desecho (mayor a 10 $\mathrm{g}$ ), el insecto y el desecho fueron separados mediante un tamiz y los correspondientes desechos se almacenaron a condiciones de humedad controlada a temperatura ambiente.

La extracción acuosa de los componentes del desecho fue realizada de la siguiente forma: se tomaron 10 gramos de cada desecho, se colocaron en un vaso de precipitados de $250 \mathrm{~mL}$ y se adicionaron $150 \mathrm{~mL}$ de agua destilada, se colocaron en una agitador magnético corning PC-420D con agitación constante en nivel medio durante 12 horas (este proceso fue realizado recubierto de aluminio para evitar oxidación por luz). Transcurrido el tiempo de agitación, las soluciones fueron centrifugadas en un centrífuga Dragon Lab DMO 412 a 3500 rpm y posteriormente filtradas con acrodisco de 0.45 micras. El filtrado se llevó a una autoclave autoclave electrónica Lorma ® modelo AV28L para su esterilización a $134{ }^{\circ} \mathrm{C}$ a $2.3 \mathrm{Kg} / \mathrm{cm}^{2}$ de presión durante 7 minutos y el desecho así tratado fue almacenado en refrigeración en un refrigerador Imbera modelo VR25C BMAD a $4{ }^{\circ} \mathrm{C}$ para su posterior uso.

\section{Síntesis de nanopartículas de plata}

Se preparó una disolución madre de $\mathrm{AgNO}_{3}$ $0.1 \mathrm{M}$ a partir de la cual se prepararon disoluciones stock de $0.1,0.2,0.3,0.4$ y $0.5 \mathrm{mM}$. La síntesis de las nanopartículas fueron realizadas según se describe a continuación: se agregaron $0.5 \mathrm{ml}$ de extracto del desecho (DN, DV1 y DV2 tratados como experimentos diferentes) a 5 crioviales. Posteriormente a cada vial se agregaron $9.5 \mathrm{ml}$ de la solución de $\mathrm{AgNO}_{3}$ de las diferentes concentraciones preparadas $(0.1$ a $0.5 \mathrm{mM})$. De manera similar, se realizaron las pruebas con DV2 y DN. Una vez preparadas todas las muestras, fueron colocadas bajo la luz de la lámpara UV modelo F6T5BL JAPAN, por un tiempo de exposición continua de 2 horas. Transcurrido ese tiempo, las muestras fueron caracterizadas mediante un barrido espectral de 200-1000 nm de longitud de onda en un espectrofotómetro UV-Vis (Thermo Scientific $^{\mathrm{TM}}$ GENESYSTM $\left.10 \mathrm{~S}\right)$.
Se prepararon rejillas para análisis por microscopía por TEM y SEM.

\section{Actividad antibacteriana.}

Se evaluó la actividad antibacteriana de las nanopartículas obtenidas con los desechos mediante el método de difusión en pozos realizado en agar TSB mínimo adaptado de (de la Fuente-Salcido et al., 2012). En breve: Se usaron veinte mililitros de medio de cultivo soya tripticasa (TSB) modificado (1.5 g/L de TSB y $12 \mathrm{~g} / \mathrm{L}$ agar bacteriológico) inoculados con 140 microlitros de cultivo fresco a D.O. 600 con los microorganismos a evaluar (Escherichia coli, Pseudomonas spp. y Vibrio cholerae). Se vaciaron las placas, se realizaron los pozos con un sacabocado de $10 \mathrm{~mm}$, se dispensaron en cada pozo $100 \mathrm{uL}$ de las muestras de las nanopartículas obtenidas con los extractos, así como sus controles negativos. Las placas fueron colocadas a $4{ }^{\circ} \mathrm{C}$ durante 16 horas (para permitir la difusión) y finalmente éstas fueron colocadas a $37^{\circ} \mathrm{C}$ durante un día, para evaluar el diámetro del halo de inhibición.

\section{Resultados y discusión}

\section{Caracterización del desecho}

Los desechos obtenidos del insecto con las tres diferentes dietas se obtuvieron en forma de polvo fino de coloración café oscuro. Una vez realizada la extracción acuosa de los distintos desechos durante las 12 horas indicadas en la metotodología, se separó la fase acuosa del sedimento,removiendo toda la parte sólida insoluble. El extracto acuoso obtenido presentó una coloración ambar.

Los extractos así obtenidos fueron caracterizados mediante un barrido espectral (200 -1000 nm), en donde se observaron exclusivamente una banda de absorción a los $290 \mathrm{~nm}$ para el desecho DV1 y otra a $280 \mathrm{~nm}$ para DN y DV2.

\section{Síntesis de nanopartículas de plata}

Para la síntesis de las nanopartículas se prepararon soluciones tomando $0.5 \mathrm{ml}$ del extracto correspondiente con $9.5 \mathrm{ml}$ de $\mathrm{AgNO}_{3}$ de las diversas concentraciones. Estas soluciones presentaron una coloración más clara que el extracto concentrado sin ningún efecto aparente de reducción al mezclarse.

RAMOS-VILLA, Isabel, LOMELÍ-ROSALES, Diego Alberto, VELASCO-RAMÍREZ, Sandra Fabiola y VELAZQUEZ-JUAREZ, Gilberto. Síntesis de nanopartículas de plata reducidas con desecho producido por el insecto Ulomoides dermestoides. Revista de Energía Química y Física. 2019. 
Posteriormente se colocaron a irradiar en una lámpara UV con tiempos de 10 a 150 minutos en donde se encontró que una radiación continua de 2 horas era lo óptimo para obtener nanopartículas en solución, observando que las soluciones cambiaron su coloración a un rojo cobrizo.

\section{Caracterización de las AgNP mediante UV- vis}

Transcurrido el tiempo de síntesis de las nanopartículas éstas se caracterizaron mediante UV-VIS observándose curvas de 400 a $500 \mathrm{~nm}$. La curva característica para las AgNP en solución se presenta alrededor de los $400 \mathrm{~nm}$, zona en la cual ninguno de los tres desechos aquí presentados muestra absorción (Gráfico 1, 2 y 3, línea color rosa) por lo que las curvas obtenidas en esa región fueron directamente atribuidas a la presencia de AgNP. En las síntesis donde se utilizó $\mathrm{AgNO}_{3}$ con concentración $0.1 \mathrm{mM}$ no se observó la curva característica esperada, en ninguno de los desechos, pudiéndose deber a la baja concentración de plata para la síntesis de las AgNP.

En las AgNP sintetizadas con el desecho DN se observaron dos bandas de absorbancia, a $380 \mathrm{~nm}$ y a $500 \mathrm{~nm}$, una curva bastante ancha indicativo de la polidispersidad con las que estas nanopartículas fueron obtenidas, la cual se definine mejor con el aumento de la concentración de $\mathrm{AgNO}_{3}$, sin embargo, siempre se obtuvieron curvas con dos absorbancias que no terminaron por unificarse en una sola (Gráfico 1).

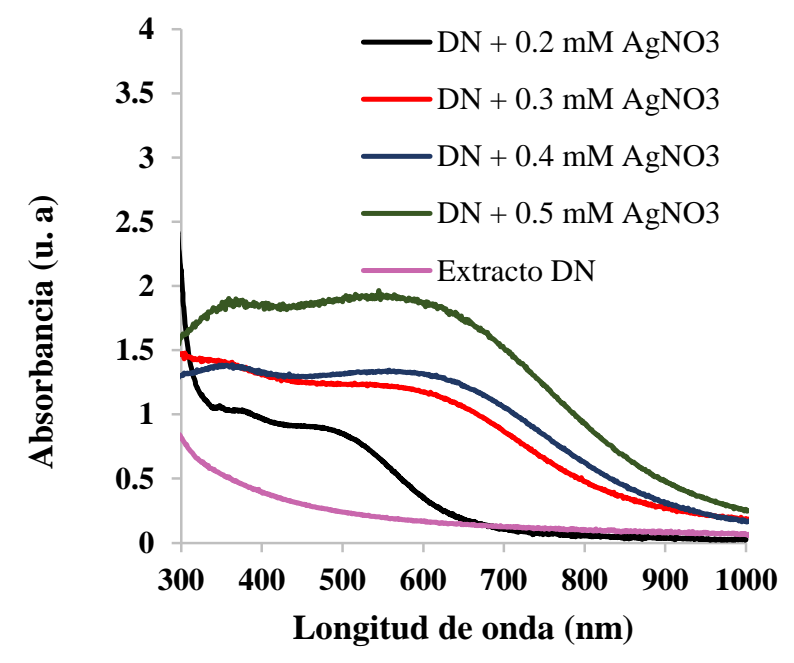

Gráfico 1 Espectro de absorción de las AgNP obtenidas con el deseño DN

Fuente: Diseño propio, generado en Excel
En aquellas síntesis utilizado DV1 (Gráfico 2) se presentaron diferencias en absorbancias dependiendo la concentración de $\mathrm{AgNO}_{3}$. En las que se utilizó $0.2 \mathrm{mM}$ se observó una curva a $400 \mathrm{~nm}$ (Gráfico 2, línea color negro). Cuando se utilizó la concentración de 0.3 $\mathrm{mM}$ se observó una curva bastante ancha y no muy bien definida con dos absorbancias, una a $400 \mathrm{~nm}$ y otra a $500 \mathrm{~nm}$ (Gráfico 2, línea color rojo).

En las que se prepararon con $0.4 \mathrm{mM}$ se observó una banda muy peculiar, presentando una meseta como máxima absorción que va desde 520 a $400 \mathrm{~nm}$, como un indicativo de nanopartículas de gran tamaño o una gran polidispersidad (Gráfico 2, línea color azul). En las síntesis con $0.5 \mathrm{mM}$ de $\mathrm{AgNO}_{3}$ se terminó por definir una única banda de máxima absorción a $450 \mathrm{~nm}$, curva característica de nanopartículas esféricas aunque de gran tamaño en este caso (Gráfico 2, línea color verde).

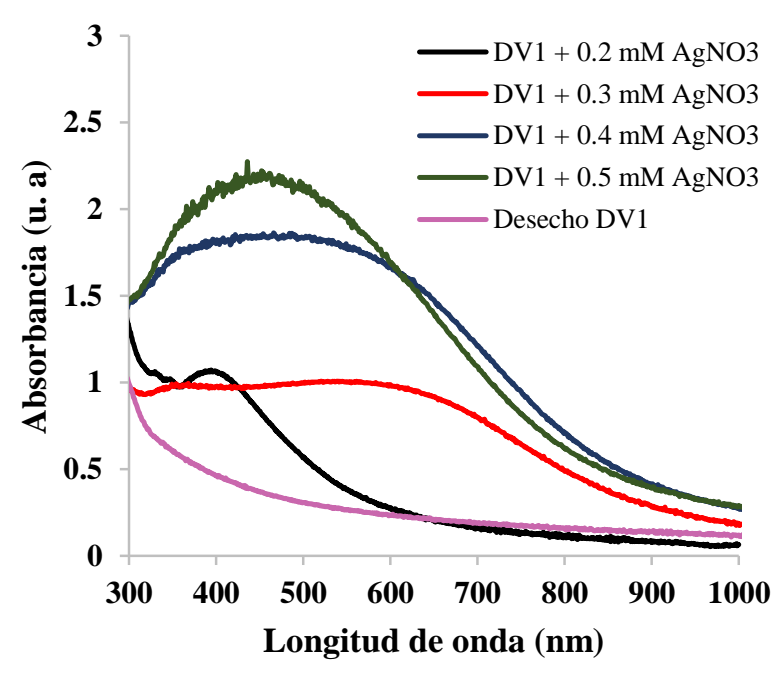

Gráfico 2 Espectro de absorción de las AgNP obtenidas con el deseño DV1

Fuente: Diseño propio, generado en Excel

En las nanopartículas donde se utilizó el desecho DV2, de igual manera que en las dos anteriores se observaron diferencias directamente relacionadas a la concentración de $\mathrm{AgNO}_{3}$ añadido para la síntesis. Sin embargo, debe señalarse que el comportamiento en las curvas de absorbancia para estas síntesis no tienen el mismo comportamiento que como con el desecho DN y DV1, ya que al incrementar la concentración de iones $\mathrm{Ag}^{+}$en disolución, las AgNP obtenidas presentaron curvas más anchas, de diferentes absorbancias y no se ajustaron al comportamiento previamente observado para AgNP con DN y DV1, en donde las curvas incrementaron su valor de absorbancia al aumentar la concentración de plata en disolución.

RAMOS-VILLA, Isabel, LOMELÍ-ROSALES, Diego Alberto, VELASCO-RAMÍREZ, Sandra Fabiola y VELAZQUEZ-JUAREZ, Gilberto. Síntesis de nanopartículas de plata reducidas con desecho producido por el insecto Ulomoides dermestoides. Revista de Energía Química y Física. 2019. 
Las curvas de absorción con $0.2 \mathrm{mM}$ resultaron con mayor absorbancia que las sintetizadas con 0.3 y $0.4 \mathrm{nM}$ de AgNO3. Mientras que las AgNP con $0.5 \mathrm{mM}$ presentaron una absorbancia del doble, pero sin lograrse definir una sola curva , un comportamiento muy semejante a las AgNP con DN (Gráfico 3).

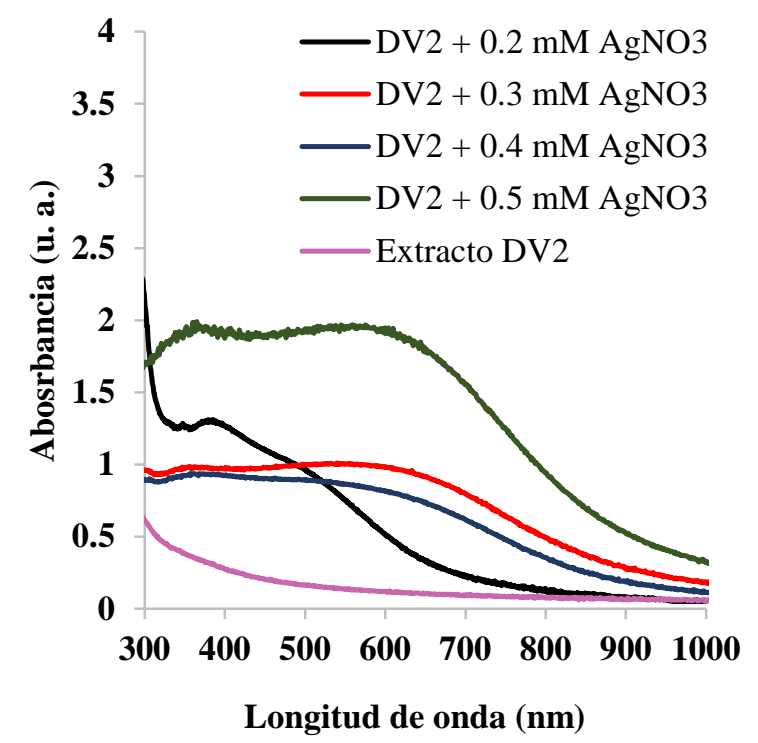

Gráfico 3 Espectro de absorción de las AgNP obtenidas con el deseño DV2

Fuente: Diseño propio, generado en Excel

\section{Caracterización de las nanopartículas mediante SEM y TEM}

Las muestras de AgNP fueron analizadas mediante SEM, en donde se observan en todos los casos, aglomeraciones de las nanopartículas obtenidas, muy probablemente debido al proceso de secado durante la preparación de la muestra. En la Figura 1 se muestra el SEM para las AgNP obtenidas con los tres desechos y concentraciones de $0.2 \mathrm{mM}$ y $0.5 \mathrm{mM}$ de $\mathrm{AgNO}_{3}$. Para todos los casos, pueden apreciarse agregados formados por nanoesferas menores a $100 \mathrm{~nm}$.

Al analizar las muestras en TEM, se corroboró lo observado en SEM, para las AgNP obtenidas con el desecho DN, se observaron nanoesferas que van desde los 5 hasta los $30 \mathrm{~nm}$ de diámetro aproximadamente, lo que justifica que las curvas de absorción de UV-vis sean anchas (Figura 2a).
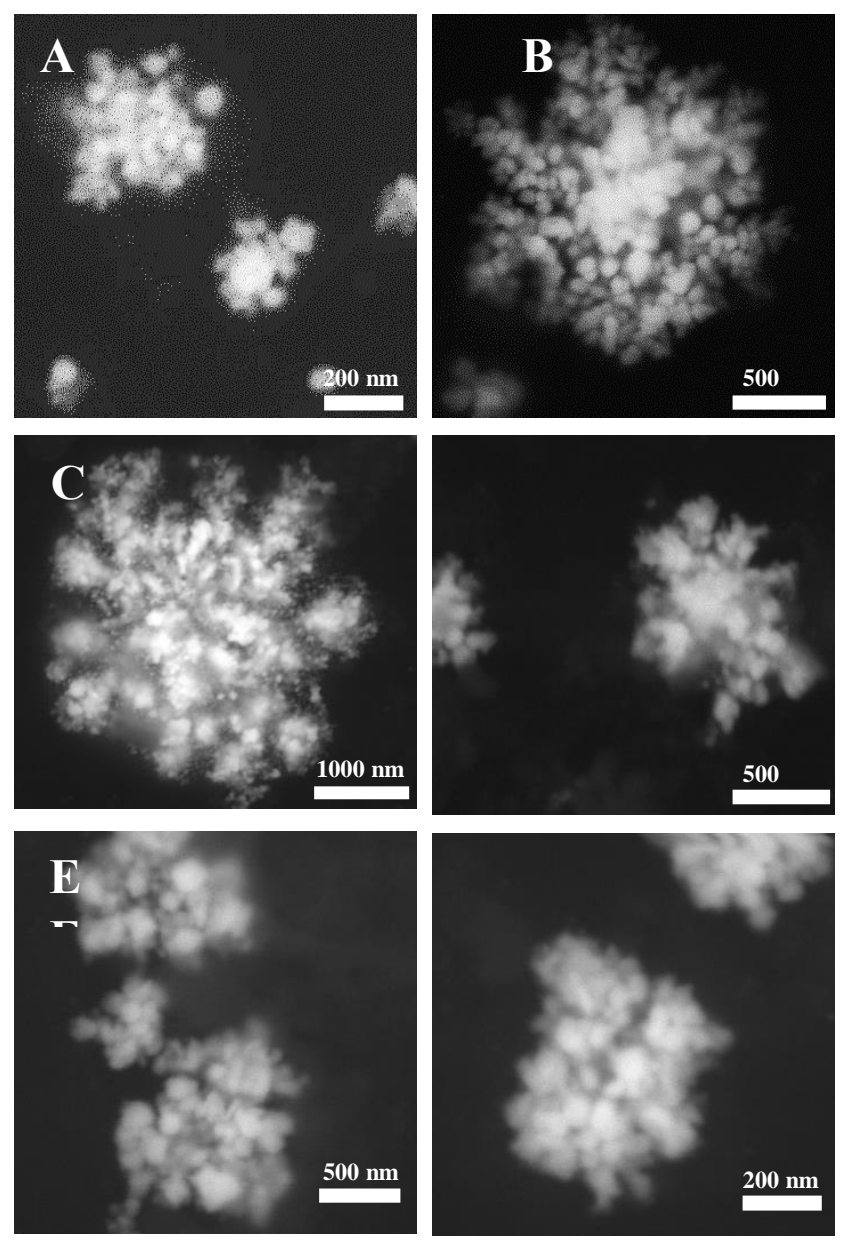

Figura 1 Imágenes SEM de las AgNP obtenidas con: desecho DN (0.2 mM (a) y $0.5 \mathrm{mM}$ (b) de $\mathrm{AgNO}_{3}$ ), desecho CV1 (0.2 mM (c) y $0.5 \mathrm{mM}$ (d) de $\left.\mathrm{AgNO}_{3}\right)$ y desecho DV2 (0.2 mM (e) y $0.5 \mathrm{mM}$ (f) de $\left.\mathrm{AgNO}_{3}\right)$. Fuente: Elaboración Propia

Para las AgNP con el desecho DV1, se obtuvieron nanopartículas esféricas de tamaños más controlados de 10 a $25 \mathrm{~nm}$, siendo la mayoría de un diámetro de aproximadamente 20 $\mathrm{nm}$, lo que justifica que en su espectro de absorción se observe una sóla banda al aumentar la concetración de iones Ag en disolución para su síntesis pues presentó menos polidispersidad (Figura 2b).

Al analizar las nanopartículas sintetizadas con DV2, se obtuvieron dos tamañaos de diámetro principalmente, 5 y 20 $\mathrm{nm}$, lo que coincide con lo observado en su espectro de absorción de UV-vis y sus dos absorbancias cerca de los 400 y $500 \mathrm{~nm}$. 

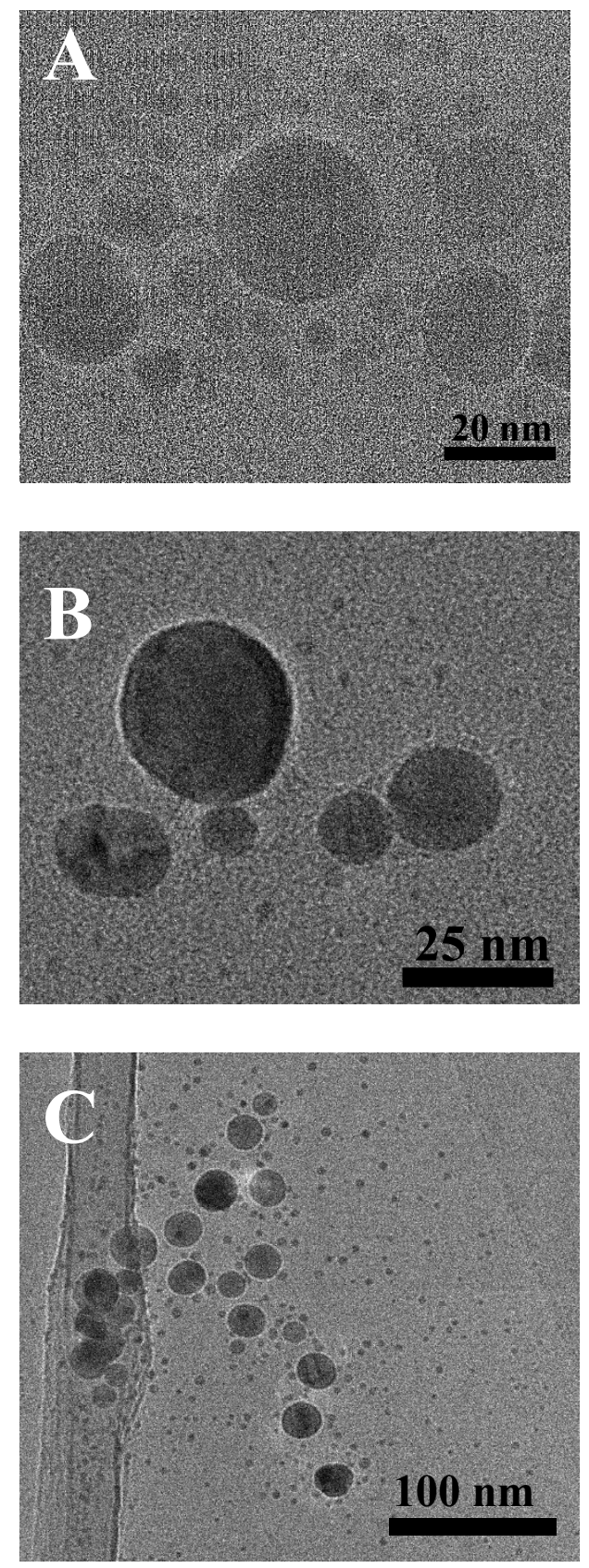

Figura 2 Imágenes TEM de las AgNp obtenidas con a) desecho DN, b) desecho CV1 y c) desecho DV2.

Fuente: Diseño propio, generado en Origin

\section{Evaluación de la Actividad antibacteriana}

Se evaluaron los halos de inhibición de las nanopartículas obtenidas con los desechos DN, DV1 y DV2, en presencia de tres microorganismos Gram negativos (Pseudomonas spp, Vibrio cholerae, E. coli), encontrándose halos de inhibición con un diámetro menor al del control de una solución de nanopartículas sintetizadas químicamente mediante citrato de sodio. Sin embargo, como se puede observar en la figura 3 , existe una diferencia entre la capacidad de inhibición del crecimiento bacteriano proporcionada con las AgNPs obtenidas con desecho DN respecto a los desechos DV1 y DV2.
Siendo este último el que mayor halo de inhibición presenta cuando se coloca contra Pseudomonas spp, no existen diferencias entre los halos de inhibición de los DV2 y DV1 en el resto de las bacterias. En todos los pozos el control negativo (desecho tratado en las mismas condiciones de la producción de las nanopartículas sin plata) no presentó actividad por sí solo.
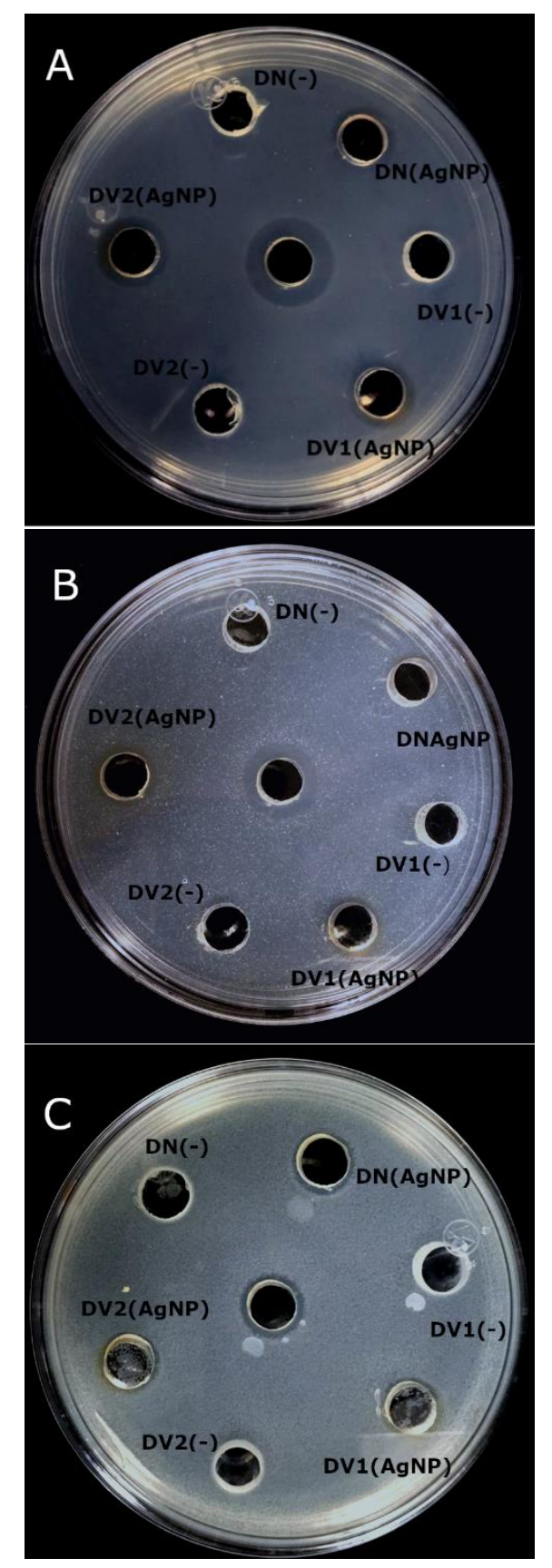

Figura 3 Ensayos de actividad antimicrobiana mediante ensayo de difusión en pozo, con las nanopartículas obtenidas con los extractos de los desechos de DN, DV1 y DV2 en concentración de $0.2 \mathrm{mM} \mathrm{AgNO}_{3}$, y sus respectivos controles de los extractos tratados bajo las mismas condiciones. A) Ensayo contra Pseudomonas spp., B) Ensayo contra Vibrio cholerae, C) Ensayo contra E. coli.

Fuente: Diseño propio, editado en GIMP 


\section{Conclusiones}

De manera exitosa se lograron obtener nanopartículas de plata utilizando el desecho del insecto Ulumoides dermestoides, una ruta sintética de un solo paso y contribuyendo a su obtención mediante procesos de química verde. Hubo diferencias importantes en las curvas espectrales para las nanopartículas obtenidas con los diversos desechos, lo cual implica que los metabolitos generados debido a la alimentación pudieran ser diferenciales.

La principal contribución de esta investigación es la apertura de un nuevo sistema de reducción $100 \%$ amigable con el medio ambiente y usando un producto de desecho de las granjas de crecimiento de insectos comestibles. Generando una línea de trabajo para la producción de nanopartículas a partir de desechos de insectos aprovechando la versatilidad metabólica del sistema. Aunque en este trabajo se explora exclusivamente el uso de plata, queda abierto el espacio para la realización de experimentos en distintos metales. La sencillez de la síntesis y el efecto diferencial de los metabolitos de los desechos permite ampliar las condiciones de síntesis para lograr procesos más rápidos y económicos.

\section{Agradecimientos}

A la Universidad de Guadalajara y al Departamento de Química por las facilidades para realizar este trabajo. Al Ing. Sergio Oliva León por su asistencia y apoyo con la caracterización por microscopías. Se agradece al CONACyT por parte de L. R. D. A. por el apoyo de beca de posgrado 292133.

\section{Sugerencias del Tema}

Se ha explorado exclusivamente el sistema de extractos acuosos de desechos (de distinto tipo) del insecto Ulumoides dermestoides, para la obtención de NPsAg, sin embargo, es necesario evaluar el poder reductor y condiciones para la producción de otro tipo de nanopartículas (mediante diversos metales, distintos a la plata), así como comparar el efecto de las dietas en el poder reductor del desecho y el uso de otros insectos pertenencientes a la misma familia de coleópteros.

\section{Referencias}

Conde Delgado, D. (2019). Desarrollo de biosensores nanoestructurados para el análisis de fenoles de interés en la industria alimentaria. Retrieved from http://uvadoc.uva.es/handle/10324/35881

Crespo, R., Villaverde, M. L., Girotti, J. R., Güerci, A., Juárez, M. P., \& de Bravo, M. G. (2011). Cytotoxic and genotoxic effects of defence secretion of Ulomoides dermestoides on A549 cells. Journal of Ethnopharmacology, 136(1), 204-209. https://doi.org/10.1016/J.JEP.2011.04.056

de la Fuente-Salcido, N. M., Barboza-Corona, J. E., Espino Monzón, A. N., Pacheco Cano, R. D., Balagurusamy, N., Bideshi, D. K., \& SalcedoHernández, R. (2012). Expanding the use of a fluorogenic method to determine activity and mode of action of Bacillus thuringiensis bacteriocins against Gram-positive and Gramnegative bacteria. TheScientificWorldJournal, 2012, 503269.

https://doi.org/10.1100/2012/503269

Gómez-Velasco, A., León-Cortés, J. L., Gordillo-Marroquín, C., Sánchez-Pérez, H. J., Alocilja Evangelyn C., Muñoz-Jiménez, S. G., ... Gómez-Bustamante, A. (2019). Uso de nanopartículas magnéticas y un biosensor para el diagnóstico y monitoreo de enfermedades infecciosas emergentes, re-emergentes y tropicales desatendidas. Rev Enf Emerg, 18(1), 23-31. Retrieved from http://www.enfermedadesemergentes.com/artic ulos/a713/ENF2019-18-

1_revision2_gomez_velasco.pdf

Gour, A., \& Jain, N. K. (2019). Advances in green synthesis of nanoparticles. Artificial Cells, Nanomedicine, and Biotechnology, 47(1), 844851.

https://doi.org/10.1080/21691401.2019.157787 8

Mlcek, J., Borkovcova, M., \& Bednarova, M. (2014). Biologically active substances of edible insects and their use in agriculture, veterinary and human medicine-a review Biologicky aktivní látky jedlého hmyzu a jejich využití v zemědělství, veterinární a humánní medicíněreview. Journal of Central European Agriculture, 15(4), 225-237. https://doi.org/10.5513/JCEA01/15.4.1533 
Morillo-Garcia, Y., Olivero-Verbel, J., \& Caballero-Gallardo, K. (2016). Life cycle of Ulomoides dermestoides (Fairmaire, 1893) (Coleoptera: Tenebrionidae) under laboratory conditions. Journal of Stored Products Research, 69, 272-275. https://doi.org/10.1016/J.JSPR.2016.09.007

Salari, Z., Danafar, F., Dabaghi, S., \& Ataei, S. A. (2016). Sustainable synthesis of silver nanoparticles using macroalgae Spirogyra varians and analysis of their antibacterial activity. Journal of Saudi Chemical Society, 20(4),

459-464.

https://doi.org/10.1016/J.JSCS.2014.10.004

Sharma, D., Kanchi, S., \& Bisetty, K. (2015). Biogenic synthesis of nanoparticles: A review. Arabian Journal of Chemistry. https://doi.org/10.1016/J.ARABJC.2015.11.002

Tello Olea, M. A. (2018). Olea, M. A. T. (2019). Actividad inmunoestimulante de nanopartículas de oro en camarón blanco (Litopenaeus vannamei) contra Vibrio parahaemolyticus. Olea, M. A. T. (2019). Actividad inmunoestimulante de nanopartículas de oro en camarón blanco (Litopenaeus vannamei) contra Vibrio parahaemolyticus. Retrieved from http://dspace.cibnor.mx:8080/bitstream/handle/ 123456789/2851/1501 tello_m TESIS.pdf?sequence $=1 \&$ isAllowed $=y$ 